\begin{tabular}{|c|l|}
\hline Title & Quantitative analysis of defective sites in titanium(IV) oxide photocatalyst powders \\
\hline Author(s) & $\begin{array}{l}\text { Ikeda, Shigeru; Sugiyama, Noboru; Murakami, Shin-ya; Kominami, Hiroshi; Kera, Yoshiya; Noguchi, Hidenori; } \\
\text { Uosaki, Kohei; Torimoto, Tsukasa; Ohtani, Bunsho }\end{array}$ \\
\hline Citation & $\begin{array}{l}\text { Physical Chemistry Chemical Physics, 5(4), 778-783 } \\
\text { https://doi.org/10.1039/0206594k }\end{array}$ \\
\hline Issue Date & 2003 \\
\hline Doc URL & http://hdl.handle.net/2115/48674 \\
\hline Rights & Phys. Chem. Chem. Phys., 2003, 5, 778-783- Reproduced by permission of the PCCP Owner Societies \\
\hline Type & article (author version) \\
\hline File Information & PCCP5_778.pdf \\
\hline
\end{tabular}

Instructions for use 
Bunsho Ohtani

Catalysis Research Center, Hokkaido University, Sapporo 060-0811, Japan

TEL: +81-11-706-3673 FAX: +81-706-4925 E-mail: ohtani@cat.hokudai.ac.jp

\section{Quantitative Analysis of Defective Sites in Titanium(IV) Oxide Photocatalyst Powders}

Shigeru Ikeda, ${ }^{\dagger \dagger}$ Noboru Sugiyama, ${ }^{\dagger}$ Shin-ya Murakami, ${ }^{\S}$ Hiroshi Kominami, ${ }^{\S}$ Yoshiya Kera ${ }^{\S}$ Hidenori Noguchi, ${ }^{\jmath}$ Kohei Uosaki, ${ }^{\rfloor}$Tsukasa Torimoto, ${ }^{\ddagger}{ }^{\dagger}$ and Bunsho Ohtani ${ }^{*},{ }^{\dagger}$

*atalysis Research Center, Hokkaido University, Sapporo 060-0811, Japan

$\dagger$ Graduate School of Environmental Earth Science, Hokkaido University, Sapporo 060-0810, Japan

$\S$ Department of Applied Chemistry, Faculty of Science and Engineering, Kinki University, Higashiosaka 577-8502, Japan

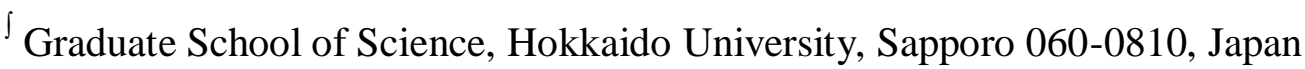

The molar amounts of defective sites $\left(\mathrm{M}_{\mathrm{d}}\right)$ in several titanium(IV) oxide $\left(\mathrm{TiO}_{2}\right)$ powders were determined using photoinduced reaction of electron accumulation in deaerated aqueous solutions containing sacrificial hole scavengers and subsequent reduction of methylviologen to its cation radical. The measurements of $\mathrm{pH}$ dependence of typical anatase and rutile $\mathrm{TiO}_{2}$ powders showed that these defective sites were of electronic energy just below the conduction band edge of $\mathrm{TiO}_{2}$ in ranges of $0-0.35 \mathrm{~V}$ for anatase and $0-0.25 \mathrm{~V}$ for rutile. A linear relation of $\mathrm{M}_{\mathrm{d}}$ with the rate constant of electron-hole recombination determined by femtosecond pump-probe diffuse reflection spectroscopy revealed that $M_{d}$ could be a quantitative parameter of recombination between a 
photoexcited electron and a positive hole. The tendency for $\mathbf{M}_{\mathrm{d}}$ to increase, but not proportionally, with increase in the specific surface area suggested that these defective sites are mainly located near the external surfaces of $\mathrm{TiO}_{2}$ particles. A reciprocal correlation between photocatalytic activity for water oxidation in aqueous silver sulfate solution and $\mathrm{M}_{\mathrm{d}}$ revealed that the rate of recombination is one of the predominant physical properties governing the activities of $\mathrm{TiO}_{2}$ powders in this reaction system.

\section{Introduction}

Polycrystalline titanium(IV) oxide $\left(\mathrm{TiO}_{2}\right)$ has been widely used as semiconductor photocatalysts in liquid-solid as well as in gas-liquid regimes ${ }^{1-9}$ because of its sufficient photostability in various circumstances, nontoxicity for environments, and potent ability to induce various types of redox reactions. ${ }^{10,11}$ It is well known that photocatalytic activity strongly depends on bulk and surface physicochemical properties of the $\mathrm{TiO}_{2}$ powder, such as the kind of crystal structure, ${ }^{12-15}$ surface area and particle size, ${ }^{16-20}$ and surface hydroxyls. ${ }^{21-23}$ Consequently, development of $\mathrm{TiO}_{2}$-photocatalytic systems with high efficiency by controlling the nature of $\mathrm{TiO}_{2}$ is one of the most attractive targets of fundamental studies in this field.

A photocatalytic reaction is initiated by the generation of electron-hole $\left(e^{-}-h^{+}\right)$ pairs by means of band-gap photoirradiation which can give rise to redox reactions with adsorbed species on the surface of the catalysis in competition with their disappearance due to mutual $\mathrm{e}^{-}-\mathrm{h}^{+}$recombination. Thus, amount of adsorbed substrates and kinetic parameters for $\mathrm{e}^{-} \mathrm{h}^{+}$recombination, e.g., lifetime and rate constant, might also be important factors to control photocatalytic activities. Actually, in our previous studies, ${ }^{16,22,24-27}$ we have demonstrated that the overall rate of photocatalytic reactions in some liquid systems is governed by capture of electrons and positive holes by a surface adsorbed substrate(s) and $\mathrm{e}^{-}-\mathrm{h}^{+}$recombination. Moreover, this implies that a highly 
active $\mathrm{TiO}_{2}$ photocatalyst should possess two properties simultaneously: a large surface area to absorb a substrate and a high degree of crystallinity (or few surface and bulk defects) to reduce $\mathrm{e}^{-}-\mathrm{h}^{+}$recombination. This working hypothesis has been supported by highly active $\mathrm{TiO}_{2}$ photocatalysts synthesized by a novel method, hydrothermal crystallization in organic media (HyCOM). ${ }^{7,28,29}$

Compared with measurement of the amount of adsorbed substrates (or the specific surface area), measurement of kinetic parameters of $\mathrm{e}^{-}-\mathrm{h}^{+}$recombination seems rather difficult, mainly due to the limitation of time resolution in conventional techniques. Electron paramagnetic resonance (EPR) spectroscopy has been used for detecting active species generated by photoirradiation of $\mathrm{TiO}_{2}$ particles in the initial step of the photocatalytic reaction. ${ }^{30-35}$ These EPR studies have revealed that electrons are trapped on the surfaces and/or inside titanium atoms, thus forming $\mathrm{Ti}^{3+}$ species, ${ }^{30-34}$ while positive holes are trapped by oxygen atoms in the crystalline lattice and/or surface hydroxyl groups. ${ }^{32,34,35}$ Based on these findings, the reaction pathways of photocatalytic processes, especially for a photooxidation system, have been discussed and clarified in some aspects. ${ }^{35}$

An alternative approach to determine $\mathrm{e}^{-}-\mathrm{h}^{+}$behavior is to directly observe the dynamics of heterogeneous electron transfer on $\mathrm{TiO}_{2}$ particles using ultrafast laser spectroscopy. Femtosecond pump-probe (PP) spectroscopy for $\mathrm{TiO}_{2}$ particles and colloids ${ }^{36-43}$ has shown that certain surface sites trap electrons within a few tens of fs after the photoexcitation, giving a broad absorption at around $500-650 \mathrm{~nm},{ }^{44,45}$ and that their recombination with positive holes induces decay of absorption within 100 ps with second-order kinetics. ${ }^{39,40}$ By analyzing the decay kinetics of opaque $\mathrm{TiO}_{2}$ powders measured in a diffuse reflection (DR) mode, we have proved that a kinetic parameter, rate constant of the absorption decay, could be a quantitative measure of the rate of $\mathrm{e}^{-}-\mathrm{h}^{+}$ recombination. ${ }^{40,41}$ Recently, reaction kinetics of trapped electrons in $\mathrm{TiO}_{2}$ powders in a time domain from microseconds to milliseconds are also characterized by a 
time-resolved IR absorption spectroscopy which allow to directly observe reaction kinetics of electron transfer from $\mathrm{TiO}_{2}$ to substrates such as $\mathrm{O}_{2}$ and $\mathrm{H}_{2} \mathrm{O}$. ${ }^{46}$

One of the most important problems encountered to above mentioned spectroscopic techniques is the complexity of the measurement procedures for using as a general method for determining kinetic parameters of $\mathrm{e}^{-} \mathrm{h}^{+}$recombination. Our research interest has, therefore, been focused on developing an easy method other than above spectroscopic techniques for obtaining a quantitative measure of the rate of $\mathrm{e}^{-}-\mathrm{h}^{+}$ recombination. In the present study, the usefulness of a method for determining the molar amount of defective sites $\left(\mathrm{M}_{\mathrm{d}}\right)$ of $\mathrm{TiO}_{2}$ powder by means of photoinduced reaction of electron accumulation in $\mathrm{TiO}_{2}$ in deaerated aqueous suspensions in the presence of a sacrificial hole scavenger was examined. Moreover, an example of correlation between photocatalytic activity and $M_{d}$ was investigated.

\section{Experimental Section}

Materials. Several kinds of titanium oxide $\left(\mathrm{TiO}_{2}\right)$ powders, those from commercial sources (Degussa P-25, Merck, Ishihara CR-EL, and Hombikat UV-100), reference catalysts supplied from the Catalysis Society of Japan (JRC-TIO-1, -2, -3, and -5), and powders synthesized by the HyCOM method ${ }^{6,28,29}$ followed by a calcination at $1073 \mathrm{~K}$

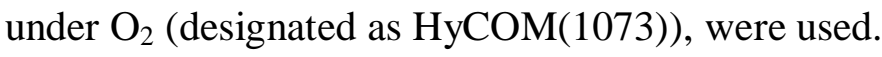

Measurement of the amount of accumulated electrons in photoirradiated $\mathrm{TiO}_{2}$. A $50 \mathrm{mg}$ portion of $\mathrm{TiO}_{2}$ powder was suspended in an aqueous solution $\left(5 \mathrm{~cm}^{3}\right)$ containing a sacrificial hole scavenger, triethanolamine (TEOA, Wako Pure Chemical, 10 vol\%) or methanol (Wako, $50 \mathrm{vol} \%$ ), and the suspension was irradiated by a high-pressure mercury arc (Eiko-sha, $400 \mathrm{~W})$ under argon (Ar). The photoirradiation was performed through a cylindrical Pyrex glass filter and a glass reaction tube $(16 \mathrm{~mm}$ in diameter and $120 \mathrm{~mm}$ in length), so that light of wavelength $>300 \mathrm{~nm}$ reached the suspension. The 
temperature of the suspension under photoirradiation was kept at $298 \pm 0.5 \mathrm{~K}$ in a thermostatted water bath. After the irradiation, a deaerated aqueous solution $\left(0.025 \mathrm{~cm}^{3}\right)$ of methylviologen $\left(\mathrm{MV}^{2+}\right)$ hydrochloride (Tokyo Kasei, $62.5 \mu \mathrm{mol}$ ) was added to the photoirradiated suspension. The resulting pale blue suspension containing a reduced form of $\mathrm{MV}^{2+}, \mathrm{MV}^{+}$, was centrifuged and the supernatant solution was loaded in a quartz cell (light pass length, $1 \mathrm{~mm}$ ) in an Ar purged glovebox (UN-650F, United Instruments). Absorbance of the solution at $600 \mathrm{~nm}$ was measured by a sensor array photometer (LASA 20, Toa Electronics), and the molar amount of $\mathrm{MV}^{+}$. was determined using the reported value of the absorption coefficient of $\mathrm{MV}^{+} \cdot, 13700 \mathrm{dm}^{3}$ $\mathrm{mol}^{-1} \mathrm{~cm}^{-1}$ at $606 \mathrm{~nm}^{47}$ It is noted that we could not measure the $606 \mathrm{~nm}$ absorbance due to the limitation of the acceptable wavelength to measure photoabsorption in our setup. However, in a separate experiment by means of an ultraviolet and visible light spectrophotometer (Hewlett Packard HP8453), we have confirmed that there is only negligible difference between the absorption coefficient of $\mathrm{MV}^{+}$. at $606 \mathrm{~nm}$ and 600 $\mathrm{nm}$.

In a separate experiment to quantify the amount of accumulated electrons by another chemical reaction, a deaerated aqueous solution containing colloidal platinum particles was added to the photoirradiated suspension under Ar instead of the addition of $\mathrm{MV}^{2+}$. After shaking the mixture for a few minutes, the gas phase was analyzed using a gas chromatograph (GC, Shimadzu, GC-8A, equipped with an MS-5A column (GL Sciences) and a TCD detector).

PP-DR spectroscopy. Details of PP-DR spectroscopy were reported previously ${ }^{40,41}$ and are briefly summarized as follows. The light source consisted of a mode-locked Ti: sapphire laser (Spectra-Physics, Tsunami: 3960-L2S) pumped by an argon ion laser (Spectra-Physics, BeamLok: 2580C) with a regenerative amplifier system (Quantronix, 4812RGA/4823S/C), which was synchronously pumped by a mode-locked YLF laser 
(Quantronix, 527DP-H). The final output was split into two beams with almost comparable intensities in order to pump two identical optical parametric generation (OPG)/optical parametric amplification (OPA) systems (Light Conversion, TOPAS). One output beam $(620 \mathrm{~nm})$ was used as a probe beam $(1.5 \mathrm{~mJ} /$ pulse $)$, and the other was frequency-doubled in a BBO crystal to use as a pump beam $(0.1-0.03 \mathrm{~mJ} / \mathrm{pulse})$. The pump and probe beams were collinearly focused and overlapped at the sample, and the diffusely reflected probe beam was measured in air at ambient temperature. Reflectance data were accumulated and recorded as absorption, 1-R/ $R_{0}$, where $R$ and $R_{0}$ represent the intensity at a given delay and that in the absence of a pump pulse, respectively.

Photoirradiation and product analyses. The photocatalyst $(50 \mathrm{mg})$ and a $5 \mathrm{~cm}^{3}$ aqueous solution containing silver sulfate $\left(\mathrm{Ag}_{2} \mathrm{SO}_{4}\right.$ (Wako Pure Chemicals), $50 \mathrm{mmol}$ $\mathrm{dm}^{-3}$ ) were placed in a glass reaction tube (18 $\mathrm{mm}$ in diameter and $180 \mathrm{~mm}$ in length), and the suspension was photoirradiated (> $300 \mathrm{~nm}$ ) under Ar with magnetic stirring (1000 rpm). The gaseous reaction product, $\mathrm{O}_{2}$, was analyzed using a GC (Shimadzu, GC-8A, equipped with an MS-5A column and a TCD detector). Details of the procedure for the photocatalytic reaction and the product analysis were reported previously ${ }^{22}$.

\section{Results and Discussion}

\section{Electron accumulation on $\mathrm{TiO}_{2}$ powders.}

Figure 1 shows the amounts of $\mathrm{MV}^{+}$. produced from photoirradiated $\mathrm{P}-25$ and JRC-TIO-2 suspensions in deaerated aqueous TEOA (10\%) solutions photoirradiated for various periods. When a deaerated aqueous $\mathrm{MV}^{2+}$ solution was injected into the aqueous suspension of $\mathrm{TiO}_{2}$ after photoirradiation, a pale blue solution containing a reduced species of $\mathrm{MV}^{2+}, \mathrm{MV}^{+}$, was obtained. On both $\mathrm{TiO}_{2}$ powders, the amount of $\mathrm{MV}^{+}$. was saturated by extending the photoirradiation time for more than twenty hours, 
though the times required for saturation to be completed in these two samples were different. It is also notable that there was an apparent difference in the saturated amounts of $\mathrm{MV}^{+} \cdot: 50 \mu \mathrm{mol} \mathrm{g}{ }^{-1}$ on Degussa P-25 and $28 \mu \mathrm{mol} \mathrm{g}{ }^{-1}$ on JRC-TIO-2. Similar behavior, saturation by photoirradiation for more than ca. twenty hours to different amounts of $\mathrm{MV}^{+}$, was observed with other $\mathrm{TiO}_{2}$ powders, suggesting that the amount of $\mathrm{MV}^{+}$. depends on the nature of the $\mathrm{TiO}_{2}$ powder. This speculation was supported by the dependence of the saturated $\mathrm{MV}^{+}$. yield on the amount of $\mathrm{TiO}_{2}$. For example, the results for Degussa P-25 powder after $24 \mathrm{~h}$ of photoirradiation, which are shown in Fig. 2, show that a linear relation was obtained and that the slope, corresponding to the saturated amount of $\mathrm{MV}^{+}$. per unit weight of the $\mathrm{TiO}_{2}$ powder $\left(\mu \mathrm{mol} \mathrm{g}{ }^{-1}\right.$ ), was in good agreement with that obtained in the above-described time dependence shown in Fig. 1.

Figure 3 shows the time course of $\mathrm{MV}^{+}$. production on JRC-TIO-2 powder in an aqueous methanol solution. The time course in a TEOA solution plotted in Fig. 1 is also shown for comparison. Similar to the case of TEOA, the $\mathrm{MV}^{+}$. production was also saturated by photoirradiation for more than ca. $35 \mathrm{~h}$ when methanol was used. However, even though the same $\mathrm{TiO}_{2}$ powder was used, the saturated $\mathrm{MV}^{+}$. amount in methanol solution is obviously less than that obtained in the TEOA solution. On the other hand, almost the same amount of $\mathrm{MV}^{+}$. was produced by both hole-scavengers when $\mathrm{pH}$ of the methanol solution was fixed at ca. 11, which is almost the same as that of the TEOA solution $(\mathrm{pH}=\mathrm{ca} .10 .5)$, and photoirradiated for $60 \mathrm{~h}$. These results indicate that the amount of accumulated $\mathrm{MV}^{+}$. depends on $\mathrm{pH}$ of the solution but is not influenced by the nature of hole-scavengers. In order to examine in detail the influence of $\mathrm{pH}$ on $\mathrm{MV}^{+}$. production, two sets of experiments were carried out using two kinds of $\mathrm{TiO}_{2}$ powders with different crystal structures. In one set of experiments, photoirradiation was conducted at $\mathrm{pH}$ of ca. 11 for $40 \mathrm{~h}$ in the presence of TEOA or methanol, and deaerated $\mathrm{H}_{2} \mathrm{SO}_{4}$ was added after the photoirradiation in order to control $\mathrm{pH}$ of the solution. In the other set of experiments, photoirradiation was conducted at $\mathrm{pH}$ of ca. 2 for $40 \mathrm{~h}$, and 
deaerated $\mathrm{NaOH}$ was added after the photoirradiation. The results are shown in Fig. 4. When JRC-TIO-2, consisting of anatase crystallites, was used, the amount of $\mathrm{MV}^{+}$. was significantly different at $\mathrm{pH}$ of around 2-8 in both sets of experiments; almost no $\mathrm{MV}^{+}$. was produced at $\mathrm{pH}$ lower than 2 , but the amount produced gradually increased with increase in $\mathrm{pH}$. On the other hand, the $\mathrm{pH}$ dependence of CR-EL, mostly rutile crystallites, was much sharper than that of the anatase (JRC-TIO-2); a jump in $\mathrm{MV}^{+}$. yield was observed at $\mathrm{pH}$ ca. 8-10. Anyway, the agreement of $\mathrm{pH}$ dependencies in the two sets of experiments suggests that the dependence of $\mathrm{pH}$ is only due to the difference in $\mathrm{pH}$ during the reduction of $\mathrm{MV}^{2+}$, and there is no significant affect of additives such as $\mathrm{NaOH}$ and/or $\mathrm{H}_{2} \mathrm{SO}_{4}$ on the present results.

When light with energy greater than the band-gap of $\mathrm{TiO}_{2}$ is irradiated on a deaerated aqueous $\mathrm{TiO}_{2}$ suspension containing sacrificial hole scavengers in the absence of loaded effective catalyst deposits for water reduction such as platinum, a part of $\mathrm{TiO}_{2}$ particle is converted by photoexcited electrons into a reduced species of $\mathrm{Ti}^{4+}\left(\mathrm{Ti}^{3+}\right)$, i.e., electrons accumulate in some states of $\mathrm{TiO}_{2}$ in the form of $\mathrm{Ti}^{3+}$. As mentioned in the introduction section, these $\mathrm{Ti}^{3+}$ species have been detected by EPR spectroscopy. ${ }^{30-34}$ The formation of $\mathrm{Ti}^{3+}$ is also indicated by the change in color from white to blue during the photoirradiation. At present, though the detailed structures of these $\mathrm{Ti}^{3+}$ species are not clear, it is reasonable to assume that such $\mathrm{Ti}^{3+}$ species are produced by trapping of electrons at defective sites in $\mathrm{TiO}_{2}$, and the amount of accumulated electrons may therefore reflect the number of defective sites that work presumably as recombination sites of $\mathrm{e}^{-}$and $\mathrm{h}^{+}$. When a deaerated aqueous $\mathrm{MVCl}_{2}\left(\mathrm{MV}^{2+}\right)$ solution is added to this suspension containing $\mathrm{Ti}^{3+}, \mathrm{MV}^{2+}$ can be reduced by such accumulated electrons.

$$
\mathrm{Ti}^{3+}+\mathrm{MV}^{2+}=\mathrm{Ti}^{4+}+\mathrm{MV}^{+}
$$

As shown in Fig. 4, in the lower $\mathrm{pH}$ region where negligible production of $\mathrm{MV}^{+}$. was 
observed with both $\mathrm{TiO}_{2}$ suspensions, the blue color of $\mathrm{TiO}_{2}$ was unchanged, i.e., the electron transfer given by eq. (1) did not proceed. At higher $\mathrm{pH}\left(\mathrm{pH}>2\right.$ for anatase $\mathrm{TiO}_{2}$ and $\mathrm{pH}>8$ for rutile), however, the color of $\mathrm{TiO}_{2}$ particles changed to white, and a pale blue solution was obtained by the addition of $\mathrm{MV}^{2+}$. The amount of $\mathrm{MV}^{+}$. was saturated, resulting in a plateau in the $\mathrm{MV}^{+}$.- versus- $\mathrm{pH}$ curve at $\mathrm{pH}$ higher than 8 for anatase or 10 for rutile due to the elimination of electrons accumulated in defective sites of $\mathrm{TiO}_{2}$ powder by complete electron transfer to $\mathrm{MV}^{2+}$, i.e., equimolar amounts of $\mathrm{Ti}^{3+}$ and $\mathrm{MV}^{2+}$ reacted to produce $\mathrm{MV}^{+}$. at $\mathrm{pH}$ higher than 10 , corresponding to the $\mathrm{pH}$ of the 10 vol\% aqueous TEOA solution used in the first experiment as shown in Fig. 1. Therefore, the amount of $\mathrm{MV}^{+}$. produced in TEOA solution is considered to reflect the molar amount of defective sites $\left(\mathrm{M}_{\mathrm{d}}\right)$ of $\mathrm{TiO}_{2}$ powder, which should be an inherent value dependent on the nature of $\mathrm{TiO}_{2}$.

For the spontaneous electron transfer from the defective site of $\mathrm{Ti}^{3+}$ to $\mathrm{MV}^{2+}$ as depicted in eq. (1), at least the electrochemical potential of the defective sites requires to be more negative than the energy level of $\mathrm{MV}^{2+} / \mathrm{MV}^{+}$. redox couple $\left(\mathrm{E}_{\mathrm{MV}}\right)$. Thus, the observed $\mathrm{pH}$ dependencies of $\mathrm{MV}^{+}$. production suggest that the energy level of $\mathrm{Ti}^{3+}$ species have $\mathrm{pH}$ dependence, i.e., the position of electrochemical potential of defective sites in higher $\mathrm{pH}$ region $(\mathrm{pH}>8$ for anatase or $>10$ for rutile) is relatively negative as compared to the energy level of $\mathrm{MV}^{2+}$ but that in lower $\mathrm{pH}$ region $(\mathrm{pH}<2$ for anatase or $<8$ for rutile) is reversed. Assuming that negligible activation energy is required to drive the electron transfer from $\mathrm{Ti}^{3+}$ to $\mathrm{MV}^{2+}$, the molar amount of produced $\mathrm{MV}^{+}$. $\left(\mathrm{M}_{\mathrm{MV}+}, \mu \mathrm{mol} \mathrm{g}{ }^{-1}\right)$ at given $\mathrm{pH}$ corresponds to the amount of defective sites of energy level between conduction band edge of $\mathrm{TiO}_{2}$, which is identical to flat band potential of $\mathrm{TiO}_{2}\left(\mathrm{E}_{\mathrm{fb}}\right)$, and $\mathrm{E}_{\mathrm{MV}} . \mathrm{E}_{\mathrm{fb}}$ and $\mathrm{E}_{\mathrm{MV}}$ are given by the following Nernst equation:

$$
\mathrm{E}_{\mathrm{fb}}=\mathrm{E}_{\mathrm{fb}}^{0}-0.059 \mathrm{pH} \quad(\mathrm{V} \text { vs NHE}),
$$




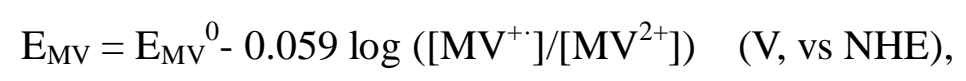

where $\mathrm{E}_{\mathrm{fb}}{ }^{0}$ and $\mathrm{E}_{\mathrm{MV}}{ }^{0}$ represent the flat band potential of $\mathrm{TiO}_{2}$ powders at $\mathrm{pH} 0\left(\mathrm{E}_{\mathrm{def}}{ }^{0}\right.$, $-0.20 \mathrm{~V}$ for anatase and $+0.04 \mathrm{~V}$ for rutile $(\mathrm{vs} \mathrm{NHE}))^{51}$ and the equilibrium potential of $\mathrm{MV}^{2+} / \mathrm{MV}^{+}$. redox couple $(-0.45 \mathrm{~V}$ vs NHE$),{ }^{52}$ respectively. The application of eq. (3) for the expression of $\mathrm{E}_{\mathrm{MV}}$ includes the assumption that the reduction of $\mathrm{MV}^{2+}$ by $\mathrm{Ti}^{3+}$ given in eq. (1) is a reversible reaction. The difference between $\mathrm{E}_{\mathrm{fb}}$ and $\mathrm{E}_{\mathrm{MV}}$ is described as

$$
\mathrm{E}=\mathrm{E}_{\mathrm{MV}}-\mathrm{E}_{\mathrm{fb}}=-0.45-0.059 \log \left(\left[\mathrm{MV}^{+\cdot}\right] /\left[\mathrm{MV}^{2+}\right]\right)-\mathrm{E}_{\mathrm{fb}}{ }^{0}+0.059 \mathrm{pH} .
$$

Accordingly, the observed $\mathrm{pH}$ dependences on both anatase and rutile $\mathrm{TiO}_{2}$ particles (Fig. 4) can be expressed as amount of $\mathrm{MV}^{+}$. production $\left(\mathrm{M}_{\mathrm{MV}_{+}}\right)$at different potentials between $E_{\mathrm{fb}}$ and $\mathrm{E}_{\mathrm{MV}}$, which are shown in Fig. 5. Since $\mathrm{E}$ can be regarded as the potential normalized by $\mathrm{E}_{\mathrm{fb}}$ as a zero standard and $\mathrm{M}_{\mathrm{MV}+}$ reflects the density of defective sites $\left(\mathrm{M}_{\mathrm{d}}(\mathrm{E}), \mu \mathrm{mol} \mathrm{g} \mathrm{g}^{-1} \mathrm{~V}^{-1}\right)$ between $\mathrm{E}_{\mathrm{fb}}$ and $\mathrm{E}_{\mathrm{MV}}$, it is clear that defective sites are distributed just below the conduction band edges of $\mathrm{TiO}_{2}\left(\mathrm{E}_{\mathrm{cb}}\right)$ and expressed as following equation:

$$
\mathrm{M}_{\mathrm{MV}+}=\int_{0}^{\mathrm{EMv}-\mathrm{Efb}} \mathrm{M}_{\mathrm{d}}(\mathrm{E}) \mathrm{dE} .
$$

A differential of eq. (5),

$$
\mathrm{M}_{\mathrm{d}}(\mathrm{E})=\mathrm{dM}_{\mathrm{MV}+} / \mathrm{dE}
$$

indicates that the density of defective sites is directly proportional to the derivative of amount of $\mathrm{MV}^{+}$. production $\left(\mathrm{dM}_{\mathrm{MV}+} / \mathrm{dE}\right)$, which provides a direct measure of the 
distribution of defective sites. Plots of $\mathrm{dM}_{\mathrm{MV}_{+}} / \mathrm{dE}$ vs $\mathrm{E}$, which were obtained by calculating $\mathrm{dM}_{\mathrm{MV}+} / \mathrm{dE}$, are shown in the insert of Fig. 5. In the anatase $\mathrm{TiO}_{2}$ (JRC-TIO-2), a relatively broad distribution of defective sites in a range of electric energy of ca. 0-0.35 $\mathrm{V}$ below $\mathrm{E}_{\mathrm{cb}}$ was obtained in comparison with the distribution in the rutile $\mathrm{TiO}_{2}(\mathrm{CR}-\mathrm{EL})$ (ca. 0-0.25 V below $\mathrm{E}_{\mathrm{cb}}$ ). Furthermore, it should be noted that the observed distributions in both $\mathrm{TiO}_{2}$ 's are shallower than that of a polycrystalline $\mathrm{TiO}_{2}$

electrode determined by an electrochemical technique (ca. 0.2-0.4 V below $\mathrm{E}_{\mathrm{cb}}$ ). ${ }^{50}$ Although further investigations are necessary to understand the predominant factor leading to these different distributions, these results suggest that the electric energy of defective sites strongly depends on the kind and/or nature of $\mathrm{TiO}_{2}$ particles.

According to the proposed reaction of eq. (1), it is expected that other reagents or reactions are also applicable for measuring the amount of $\mathrm{Ti}^{3+}$. In order to confirm this, the reduction of proton $\left(\mathrm{H}^{+}\right)$catalyzed by the addition of a platinum colloid catalyst was carried out instead of the $\mathrm{MV}^{2+}$ reduction.

$$
\mathrm{Ti}^{3+}+\mathrm{H}^{+}=\mathrm{Ti}^{4+}+1 / 2 \mathrm{H}_{2}
$$

When P-25 was used, for example, the liberation of $1.2 \mu \mathrm{mol}$ of $\mathrm{H}_{2}$ per $50 \mathrm{mg}$ of $\mathrm{TiO}_{2}$, which is almost half that of $\mathrm{MV}^{+}$, was liberated. Thus, the observed $\mathrm{MV}^{+}$. production was induced by the accumulated electrons in defective sites of $\mathrm{TiO}_{2}$ powders, and the amount of these defective sites could be quantified by the chemical reactions.

Correlation with other physical properties and photocatalytic activity. Figure 6 shows representative time profiles of $\mathrm{Merck}^{\mathrm{TiO}} 2$ powder in PP-DR spectroscopy. When a 310-nm light beam (ca. 100 fs pulse) was irradiated onto $\mathrm{TiO}_{2}$ powders, broad absorption in the visible-infrared region (In this system, diffuse reflected light at $620 \mathrm{~nm}$ was measured.) appeared and was decreased with increased time delay of the probe 
pulse at $620 \mathrm{~nm} \cdot{ }^{40-43}$ All of the $\mathrm{TiO}_{2}$ samples studied here showed similar decay profiles consisting of very rapid (< ca. $250 \mathrm{fs}$ ) rise in absorption at $620 \mathrm{~nm}$ and its gradual decay. The decay profiles could be reproduced by a second-order rate expression using the equation

$$
(\text { absorption })=\alpha\left\{\left[\mathrm{e}_{0}\right] /\left(1+\mathrm{k}_{\mathrm{r}}\left[\mathrm{e}_{0}\right] \mathrm{t}\right)+\mathrm{BL}\right\}
$$

where $\left[\mathrm{e}_{0}\right], \mathrm{k}_{\mathrm{r}}, \mathrm{t}$, and $\mathrm{BL}$ represent the initial concentration of trapped electrons, second-order rate constant $\left(\mathrm{cm}^{3} \mathrm{ps}^{-1}\right)$, time delay of the probe pulse (ps), and a component of the long-lived baseline, respectively. The parameter $\alpha\left(\mathrm{cm}^{3}\right)$ includes a photoabsorption cross section of the components and depth of penetration of the pump pulse and must vary with the measurement conditions. As has been discussed, ${ }^{40,41} \mathrm{k}_{\mathrm{r}}$ $\left(\mathrm{cm}^{3} \mathrm{ps}^{-1}\right)$ values of $\mathrm{TiO}_{2}$ powders were determined with the assumption that $\alpha$ equals unity for every sample. Table 1 summarises $\mathrm{k}_{\mathrm{r}}$ and other parameters, molar amounts of defective sites $\left(\mathrm{M}_{\mathrm{d}}, \mu \mathrm{mol} \mathrm{g} \mathrm{g}^{-1}\right)$, BET surface areas $\left(\mathrm{S}, \mathrm{m}^{2} \mathrm{~g}^{-1}\right)$, and photocatalytic activity for $\mathrm{O}_{2}$ liberation from deaerated aqueous silver sulfate solution as discussed below.

As shown in Fig. 7, an almost linear correlation of $\mathrm{k}_{\mathrm{r}}$ with $\mathrm{M}_{\mathrm{d}}$ of several $\mathrm{TiO}_{2}$ powders was observed. It is noted that there seems no specific influence on the difference of crystal structure, e.g., anatase, rutile, and their mixtures. Although details of the mechanism of $\mathrm{e}^{-}-\mathrm{h}^{+}$recombination on $\mathrm{TiO}_{2}$ photocatalysis is not clear, if it is assumed that the predominant pathway of recombination in both anatase and rutile $\mathrm{TiO}_{2}$ is that of photoexcited electrons with positive holes at defective sites, a linear relation between these parameters is reasonable. Therefore, it is concluded that $M_{d}$ can be a quantitative kinetic measure of the $\mathrm{e}^{-}-\mathrm{h}^{+}$recombination.

Figure 8 shows plots of $M_{d}$ as a function of $S$. $M_{d}$ tended to increase with increase in S, implying that the electron accumulation sites, defective sites, mainly exist near the external surface of $\mathrm{TiO}_{2}$ particles. The number of $\mathrm{Ti}$ atoms on the external 
surface of JRC-TiO-2, for example, is estimated to ca. $210 \mu \mathrm{mol} \mathrm{g}{ }^{-1}$, while $\mathrm{M}_{\mathrm{d}}$ on this $\mathrm{TiO}_{2}$ powder is $28 \mu \mathrm{mol} \mathrm{g}{ }^{-1}$ (Fig. 1); it is reasonable to assume the existence of such electron accumulation sites on the surface. Although the detailed structure is still ambiguous as mentioned above, such electron accumulation on defective sites seem to be accompanied by surface sites on $\mathrm{TiO}_{2}$ powders and the excess negative charge may be compensated by the insertion of protons $\left(\mathrm{H}^{+}\right)$from the aqueous phase ${ }^{53,54}$, and/or elimination of $\mathrm{O}^{2-}$ inons.

Previous studies have indicated that the stoichiometry of the main reactions in an aqueous suspension of $\mathrm{TiO}_{2}$ in the presence of silver ions under deaerated condition was as follows: ${ }^{22}$

$$
4 \mathrm{Ag}^{+}+2 \mathrm{H}_{2} \mathrm{O}=4 \mathrm{Ag}+4 \mathrm{H}^{+}+\mathrm{O}_{2}
$$

Consequently, we could estimate the overall rate of redox reaction by the rate of $\mathrm{O}_{2}$ liberation from its time-course curve during the initial $0.5 \mathrm{~h}$ of photoirradiation (Table 1). Figure 9 shows a plot of photocatalytic activity versus $M_{d}$. The rate of the reaction tended to decrease with increasing $\mathrm{M}_{\mathrm{d}}$, suggesting that the rate of $\mathrm{e}^{-}-\mathrm{h}^{+}$recombination might predominantly govern photocatalytic activity of this reaction, agreed well with our previous kinetic analyses. ${ }^{22}$ Therefore, it is considered that a $\mathrm{TiO}_{2}$ powder having relatively high crystallinity, low amount of defective sites, is appropriate in this type of reaction. On the other hand, it is also notable that some of $\mathrm{TiO}_{2}$ powders (JRC-TIO-2, Merck) are fairly deviated from the inversed-proportional-curve of the correlation. The specific feature of these powders might be attributed to the crystal structure, i.e., anatase $\mathrm{TiO}_{2}$ is not active for this photocatalytic reaction, and thus it is speculated that a rutile $\mathrm{TiO}_{2}$ having high crystallinity might be the most suitable photocatalyst for this type of reaction. In order to clarify the influence of the crystalline phase, detailed studies are now under way, and the results will be reported elsewhere. ${ }^{55}$ 


\section{Conclusions}

A simple method to determine the amount of defective sites of a $\mathrm{TiO}_{2}$ powder photocatalyst has been developed. These defective sites were of electronic energy just below the conduction band edge of $\mathrm{TiO}_{2}$ in ranges of $0-0.35 \mathrm{~V}$ for a typical anatase and 0.- $0.25 \mathrm{~V}$ for a typical rutile $\mathrm{TiO}_{2}$ powders. An almost linear relation of $\mathrm{M}_{\mathrm{d}}$ with the rate constant of electron-hole recombination revealed that $\mathrm{M}_{\mathrm{d}}$ could be a quantitative measure of recombination. By analyzing the correlation with photocatalytic activity for water oxidation in the presence of silver ions, it was clarified that $M_{d}$ was the predominant factor determining the photocatalytic activity of $\mathrm{TiO}_{2}$. Such correlations between photocatalytic activity and physical properties might be a specific feature of this kind of reaction, and predominant physical properties should be different among types of photocatalytic reactions. Accordingly, in order to design and predict efficient $\mathrm{TiO}_{2}$ photocatalysts in a desired reaction system, it is necessary to choose appropriate parameters of $\mathrm{TiO}_{2}$ powder.

\section{Acknowledgements}

The authors are grateful to the Catalysis Society of Japan for supplying some of the $\mathrm{TiO}_{2}$ samples. This research was partly supported by Grant-in-Aids for Encouragement of Young Scientists (No. 13750753) and for Scientific Research on Priority Areas (417, No. 14050007) from the Japan Society for the Promotion of Science (JSPS) and the Ministry of Education, Culture, Sports, Science and Technology (MEXT) of the Japanese Government, respectively. Financial support by The Sumitomo Foundation is acknowledged. Mr. Tetsuzo Habu and Mr. Kazuhiro Matsudaira (Technical Division of the Catalysis Research Center, Hokkaido University) are acknowledged for their assistance in the construction of the photoirradiation apparatuses. 


\section{References}

1. M. R. Hoffmann, S. T. Martin, W. Choi and D. W. Bahnemann, $\square$ Chem. Rev., 1995, 95, 69.

2. A. L. Linsebigler, G. Lu and J. T. Yates, $\square$ Chem. Rev., 1995, 95, 735.

3. A. Fujishima, K. Hashimoto and T. Watanabe, in $\mathrm{TiO}_{2}$ Photocatalysis -Fundamentals and Applications, BKC, Tokyo, 1999, 176.

4. Energy Resources through Photochemistry and Catalysis, ed. M. Grätzel, Academic Press, Yew York, 1983.

5. S. Tabata, H. Nishida, Y. Masaki and K. Tabata, $\square$ Catal. Lett., 1995, 34.

6. H. Kominami, S.-y. Murakami, M. Kohno, Y. Kera, K. Okada, and B. Ohtani, $\square$ Phys. Chem. Chem. Phys., 2001, 3, 4102.

7. R. Abe, K. Sayama, K. Domen and H. Arakawa, Chem. Phys. Lett., 2001, 344, 339.

8. M. A. Fox and M. T. Dulay, $\square$ Chem. Rev., 1993, 93, 341.

9. B. Ohtani, S. Kusakabe, K. Okada, S. Tsuru, S.-i. Nishimoto, Y. Amino, K. Izawa, Y. Nakato, M. Matsumura, Y. Nakaoka and Y. Nosaka, $\square$ J. Chem. Soc., Perkin Trans. 2, 2001, 201.

10. A. Mills and P. Sawunyama, $\square$ J. Photochem. Photobiol. A: Chem., 1997, 108, 1.

11. Heterogeneous Photocatalysis, ed. M. Schiavello, John Wiley \& Sons, Chichester, 1997.

12. A. Mills, R. H. Davies and D. Worsley, $\square$ Chem. Soc. Rev., 1993, 417.

13. S.-i. Nishimoto, B. Ohtani, H. Kajiwara and T. Kagiya, $\square$ J. Chem. Soc., Faraday Trans. 1, 1985, 81, 61 .

14. R. I. Bickley, T. Gonzalez-Carreno, J. S. Lees, L. Palmisano and R. J. D. Tilley, $\square$ J. Solid State Chem., 1991, 92, 178.

15. M. V. Rao, K. Rajeswar, V. R. Pai Verneker and J. DuBow, $\square$ J. Phys. Chem., 1980, 
84, 1987.

16. B. Ohtani, S.-w. Zhang, S.-i. Nishimoto, and T. Kagiya, $\square$ J. Photochem. Photobiol., A: Chem., 1992, 64, 223.

17. T. Sakata, T. Kawai and K. Hashimoto, $\square$ Chem. Phys. Lett., 1982, 88, 50.

18. B. Ohtani, J.-i. Handa, S.-i. Nishimoto and T. Kagiya, $\square$ Chem. Phys. Lett., 1985, 120, 292.

19. A. Sclafani, L. Palmisano and M. Schiavello, $\square$ J. Phys. Chem., 1990, 94, 829.

20. K. Tanaka, M. F. V.Capule and T. Hisanaga, $\square$ Chem. Phys. Lett., 1991, 187, 73.

21. Y. Oosawa and M. Grätzel, $\square$ J. Chem. Soc., Chem. Commun., 1984, 1629.

22. B. Ohtani, Y. Okugawa, S.-i. Nishimoto and T. Kagiya, $\square$ J. Phys. Chem., 1987, 91, 3550.

23. Y. Oosawa and M. Grätzel, $\square$ J. Chem. Soc., Faraday Trans. 1, 1988, 84, 197.

24. S.-i. Nishimoto, B. Ohtani, H. Kajiwara and T. Kagiya, $\square$ J. Chem. Soc., Faraday Trans. 1, 1983, 79, 2685.

25. B. Ohtani, M. Kakimoto, H. Miyadzu, S.-i. Nishimoto and T. Kagiya, $\square$ J. Phys. Chem., 1988, 92, 5773.

26. B. Ohtani and S.-i. Nishimoto, $\square$ J. Phys. Chem., 1993, 97, 920.

27. B. Ohtani, K. Tennou, S.-i. Nishimoto and T. Inui, $\square$ J. Photosci. 1995, 2, 7.

28. H. Kominami, T. Matsuura, K. Iwai, B. Ohtani, S.-i. Nishimoto and Y. Kera, $\square$ Chem. Lett., 1995, 693.

29. B. Ohtani, K. Iwai, H. Kominami, T. Matsuura, Y. Kera and S.-i. Nishimoto, Chem. Phys. Lett., 1995, 242, 315.

30. R. F. Howe and M. Grätzel, J. Phys. Chem., 1985, 89, 4495.

31. R. F. Howe and M. Grätzel, J. Phys. Chem., 1987, 91, 5889.

32. O. I. Micic, Y. Zhang, K. R. Cromack, A. D. Trifunac and M. C. Thurnauer, $\square J$. Phys. Chem., 1993, 97, 13284.

33. J. Kiwi, J. T. Suss and S. Szapiro, $\square$ Chem. Phys. Lett., 1984, 106, 135. 
34. Y. Nakaoka and Y. Nosaka, $\square$ J. Photochem. Photobiol., A: Chem., 1997, 110, 299.

35. Y. Nosaka, M. Kishimoto and J. Nishino, $\square$ J. Phys. Chem. B., 1998, 102, 10279.

36. D. E. Skinner, D. P. Colombo Jr., J. J. Cavaleri and R. M. Bowman, $\square$ J. Phys. Chem., 1995, 99, 7853.

37. D. P. Colombo Jr. and R. M. Bowman, $\square$ J. Phys. Chem., 1995, 99, 11752.

38. D. P. Colombo Jr., K. A. Roussel, J. Saeh, D. E. Skinner, J. J. Cavaleri and R. M. Bowman, $\square$ Chem. Phys. Lett., 1995, 232, 207.

39. D. P. Colombo Jr. and R. M. Bowman, $\square$ J. Phys. Chem., 1996, 100, 18445.

40. B. Ohtani, H. Kominami, R. M. Bowman, D. P. Colombo Jr., H. Noguchi and K. Uosaki $\square$ Chem. Lett., 1998, 579.

41. S. Ikeda, N. Sugiyama, B. Pal, G. Marci, L. Palmisano, H. Noguchi, K. Uosaki and B. Ohtani, $\square$ Phys. Chem. Chem. Phys., 2001, 3, 267.

42. A. Furube, T. Asahi, H. Masuhara, H. Yamashita and M. Anpo, $\square$ Chem. Lett., 1997,735 .

43. A. Furube, T. Asahi, H. Masuhara, H. Yamashita, M. Anpo, $\square$ J. Phys. Chem. B., 1999, 103, 3120.

44. G.. Rothenberger, J. Moser, M. Grätzel, N. Serpone, N. and D. K. Sharma, $\square J . A m$. Chem. Soc., 1985, 107, 8054.

45. N. Serpone, D. Lawless, R. Khairutdinov, $\square$ J. Phys. Chem., 1995, 99, 16655.

46. A. Yamakata, T.-a. Ishibashi and H. Onishi, $\square$ J. Phys. Chem. B., 2001, 105, 7258.

47. T. Watanabe and K. Honda, $\square$ J. Phys. Chem., 1982, 86, 2617.

48. H. Kominami, J.-i. Kato, M. Kohno, Y. Kera and B. Ohtani, $\square$ Chem. Lett., 1996, 1051.

49. S.-i. Nishimoto, B. Ohtani, H. Kajiwara and T. Kagiya, J. Chem. Soc., Faraday Trans. 1, 1985, 81, 2467.

50. H. Wang, J. He, G. Boschloo, H. Lindström, A. Hagfeldt, S.-E. Lindquist, J. Phys. Chem. B, 2001, 105, 2529, and references are therein. 
51. L. Kavan, M. Grätzel, S. E. Gilbert, C. Klemenz and H. J. Scheel, J. Am. Chem. Soc., 1996, 118, 6716.

52. A. J. Bard, in Standard Potentials in Aqueous Solution, ed. M. Delder, New York; $1985,49$.

53. B. I. Lemon and J. T. Hupp, J. Phys. Chem., 1996, 100, 14578.

54. B. I. Lemon and J. T. Hupp, J. Phys. Chem., 1997, 101, 2426.

55. T. Torimoto, N. Nakamura, S. Ikeda and B. Ohtani, to be published.

\section{Figure Captions}

Fig. 1. Plots of molar amount of $\mathrm{MV}^{+}$. versus photoirradiation time. Upper, Degussa P-25; lower, reference $\mathrm{TiO}_{2}$ catalyst, JRC-TIO-2, supplied by the Catalysis Society of Japan.

Fig. 2. Plots of molar amount of $\mathrm{MV}^{+}$. as a function of amount of $\mathrm{TiO}_{2}$ powder. Catalyst, Degussa P-25; photoirradiation time, 24 h. Slope denotes molar amount of $\mathrm{MV}^{+}$. per unit weight of the catalyst powder.

Fig. 3. Plots of molar amount of $\mathrm{MV}^{+}$. from a deaerated aqueous solution of TEOA (A) and methanol (B) versus photoirradiation time. Open circles, TEOA aq. ( $\mathrm{pH}=\mathrm{ca}$. 10.5); filled diamonds, methanol aq. $(\mathrm{pH}=\mathrm{ca} .7 .0)$; open diamonds, methanol aq. $(\mathrm{pH}=$ ca. 11.0). Catalyst, JRC-TIO-2.

Fig. 4. Dependence of the amount of $\mathrm{MV}^{+}$. production on solution $\mathrm{pH}$. Upper, anatase $\mathrm{TiO}_{2}$ (JRC-TIO-2); lower, rutile $\mathrm{TiO}_{2}$ (CR-EL). Open squares, photoirradiaton at $\mathrm{pH}$ of ca. 11; filled squares, photoirradiaton at $\mathrm{pH}$ of ca. 2.

Fig. 5. The amount of $\mathrm{MV}^{+}$. production at different potentials based on the flat band potential of $\mathrm{TiO}_{2}$. Upper, anatase $\mathrm{TiO}_{2}$ (JRC-TIO-2); lower, rutile $\mathrm{TiO}_{2}$ (CR-EL). The inserts show $\mathrm{dM}_{\mathrm{MV}_{+}} / \mathrm{dE}$ distribution against potentials. The meanings of symbols are the same as those in Fig.4. 
Fig. 6. Representative decay profiles of $\mathrm{TiO}_{2}$ powders induced by an ultrafast pump (ca. 100 fs). Sample, Merck $\mathrm{TiO}_{2}$. Solid line indicates the fitting with eq. (8).

Fig. 7. Relation between $M_{d}$ and $k_{r}$. (a) Degussa P-25, (b) Merck, (c) JRC-TIO-2, (d) JRC-TIO-5, (e) HyCOM(1073). Open circles, filled circles, and filled diamonds denote anatase, rutile, and their mixtures, respectively.

Fig. 8. Relation between $S$ and $\mathrm{M}_{\mathrm{d}}$. (a) Degussa P-25, (b) Merck, (c) JRC-TIO-2, (d) JRC-TIO-5, (e) HyCOM(1073), (f) UV-100, (g) CR-EL, (h) JRC-TIO-1, (i) JRC-TIO-3. The meanings of symbols are the same as those in Fig.7.

Fig. 9. Rate of $\mathrm{O}_{2}$ evolution on several $\mathrm{TiO}_{2}$ powders versus $\mathrm{M}_{\mathrm{d}}$. The meanings of characters and symbols are the same as those in Fig.'s 7 and 8. 